\title{
Sizing implications of a regional aircraft for inner-city
}

\section{operations}

\begin{abstract}
Purpose - The paper aims to assess the potential of aircraft operation from city centres to achieve shortened travel times and the involved aircraft design process.

Design/methodology/approach - The paper describes the methodical approach and iterative procedure of the design process. An assessment of potential technologies is conducted to provide the required enhancements to fulfil the constraints following an inner-city operation. Operational procedures were analysed to reduce the noise propagation through flight path optimization. Furthermore a ground based assisted take-off system was conceived to lower required take-off field length and to prevent engine sizing just for the take-off case. Cabin design optimization for a fast turnaround has been conducted to ensure a wide utilization spectrum. The results prove the feasibility of an aircraft developed for inner-city operation.
\end{abstract}

Findings - A detailed concept for a 60 passenger single aisle aircraft is proposed for an Entry-Into-Service year 2040 with a design range of 1,500 nautical miles for a load factor of $90 \%$. Although the design for STOL and low noise operation had to be traded partly with cruise efficiency, a noteworthy reduction in fuel burn per passenger and nautical mile was achieved against current aircraft.

Practical implications - The findings will contribute to the evaluation of the feasibility and impact of the Flightpath 2050 goal of a four hour door-to-door by providing a feasible but ambitious example. Furthermore, it highlights possible bottlenecks and problems faced, when realizing this goal.

Originality/value - The paper draws its value from the consideration of the overall sizing effects at aircraft level and from a holistic view on an inner-city airport/aircraft concept.

Keywords Aircraft Design, Regional, STOL, Low Noise, annexed Technologies.

Paper type Technical Paper. 


\section{Introduction}

One major goal of the European Commission's Flight Path 2050 document is that $90 \%$ of travellers should be able to reach a destination within Europe in four hours from door-to-door (European commission, 2011). This goal requires optimization with respect to both aircraft and airport technologies as well as a perfect fit of both. To this end, an interdisciplinary group design project at Bauhaus Luftfahrt was initiated to develop a feasible solution for the proposed goal. Within the project, a comprehensive study of a novel aircraft and airport concept has been conducted. Four key drivers are setting the scene of this group design project:

1. Four hours door-to-door travel time for inner-European flights and associated connecting transport modes needs to be achieved.

2. Different air traffic forecasts predict global growth rates to be around $4.7 \%$ per year. Until 2040 this means that air traffic will triple. (Airbus S.A.S., 2012, Boeing, 2012, Airport Council International, 2012, ICAO, 2007, RollsRoyce, 2009)

3. Urbanization and a growing number of megacities are already an important driver of today's transport challenges but will become even more important up to and beyond 2040 as raising agglomeration in cities is meant to result in a share of $2 / 3$ of the global population to live in cities. (United Nations, 2010)

4. The geographical location of airports as well as the related airport connectivity in combination with the on-going agglomeration in megacities is a key challenge to meet the fast growing air transport demand until 2040 at these air transport nodes.

These key drivers indicate that there is a need for an air transport concept which is located near city centres, supports global air traffic growth and urbanization challenges and, thus, is a mass transportation mode connecting major city-pairs, and ensures door-to-door travel times of less than four hours.

For the 100 biggest cities in Europe, Asia and North America, available space was analysed near the city centres which could be used as an inner-city airport, called "CentAirStation". Spaces with sufficient dimensions had been found in each of the 30 biggest cities in Europe around six times on average (Table 2). As most available spaces are located above train tracks of inner-city train stations, such locations enable smooth connections from and to inner-city transport modes. Therefore, a CentAirStation is a four level building with the train station on the $1^{\text {st }}$ floor, a public level with shops and security checks on the $2^{\text {nd }}$ floor, the apron level on the $3^{\text {rd }}$ floor and the runway level on the roof. Passengers can board an aircraft via a gate on the apron level which is linked by security tunnels starting on the public level. Aircraft are moved by taxi robots from the gates on the apron level to one of the four elevators in each corner of the apron level up to the runway level. Further information regarding the CentAirStation concept can be found in (Urban, 2016). In order to obtain public 
acceptance of aircraft movements in city centres, such aircraft need to reduce their negative impact, like $\mathrm{CO}_{2}, \mathrm{NOx}$ and noise emissions significantly. Thus, a novel and perfectly adopted aircraft - the "CityBird" - which can be operated at CentAirStations as well as at conventional airports was necessary.

The CityBird concept is described in detail in the chapter "Concept Description" after the definition of aircraft top level requirements and a brief market assessment. The chapter "Performance" looks closely at the flight performance of a CityBird and limiting constraints. Finally a conclusion is drawn and an outlook to future work is given.

\section{Aircraft Top Level Requirements}

The definition of the aircraft top level requirements (ATLeRs) shows how many requirements and constraints were within the context of this project. In this section, the process of top level requirement definition is outlined. Since the aircraft aims to address mass transport for all passenger groups, the potential and the market size in terms of possible customers was analysed. It also serves primarily as a city-to-city connection and aims to be a slot relief concept at major airports freeing up capacity for further hub operations, especially on longer ranges. Therefore, economic considerations were taken into account. The growth of the aviation market was considered by using the average of eleven market forecasts (Schmidt, 2013) predicting growth until 2030 and an extrapolation towards 2040 on revenue passenger kilometres (RPK) for the economically most interesting regions in the world. This includes the North American continent, Europe and Asia. A worldwide growth rate of $4.7 \%$ per year is expected. Table 1 shows the growth rate by region and the growth of frequencies and installed seats per aircraft taken as an average of the before mentioned aviation forecasts until 2030.

Table $1 \quad$ Forecasted aviation growth (Schmidt, 2013)

\begin{tabular}{lccc}
\hline Region & Annual RPK Growth & $\begin{array}{l}\text { Growth in Frequency by } \\
\text { 2030 }\end{array}$ & $\begin{array}{l}\text { Growth in average installed seats } \\
\text { by 2030 } \\
\text { (Airport } \\
\text { Council }\end{array}$ \\
& & & +70 (n) \\
\hline Europe & $4.1 \%$ & $+146 \%$ & $+15 \%$ \\
Asia & $6.2 \%$ & $+36 \%$ & $+5 \%$ \\
North America & $3.0 \%$ & & $5 \%$ \\
\hline
\end{tabular}

An analysis from Official Airline Guide (OAG) of 2012 (OAG, 2012) data resulted in the number of offered RPK from every analysed city pair with a range equal or lower than the desired design range of the aircraft concept. In combination with the forecasted growth rate, this led to design capacity of a CentAirStation of 10.5 million passengers per year. Assuming a 16 hour operation of the airport per day and a normal frequency for departures and arrivals at the airport, a capacity of 60 passengers per aircraft is deemed necessary. A more detailed analysis of the airport passenger capacity estimation can be found in (Urban, 2016). 
To ensure interconnection of the most important cities within a region concerning passenger flow, the range had to be appropriately sized. An analysis shows the need for a 1,500 NM range to connect most of the major cities in the aforementioned three regions. Although the average stage length today flown by Airbus A320 in Europe is 480 NM for Low Cost Carriers, respectively 600 NM for Full Service Carriers (OAG, 2012), the high range for a regional sized aircraft is justified by the four hour door-to-door travel time, thus avoiding stop-overs which are time consuming. Although the A320 has a greater passenger capacity and range, it serves as a main city connecter nowadays and is therefore suited for comparison.

The cruise speed is defined by the goal of a four hour door-to-door travel time and the range. This includes block time, boarding/deboarding times, time within the airport while arriving or departing, and time from the starting point of the journey to the airport and to the final destination. Hence, the airport and aircraft concept should be designed to shorten access times. Figure 1 shows the block time in relation to the flight distance for Mach numbers of M0.60 and M0.66 compared to a conventional profile flown by an Airbus A320 (M0.76). The diagrams show that an additional time of 48 minutes is needed for a $1,500 \mathrm{NM}$ journey, if the cruise speed is M0.60 compared to an A320. For a cruise speed of M0.66 this is reduced to 28 minutes. The flight time for $1,500 \mathrm{NM}$ exceeds the four hour goal already on block time. It is equal to four hours at 1,250 NM for M0.66 and 1,131 NM for M0.6. Not included are the times for the journey to and from the airport further lowering the 4-hour-range. Since the highest utilization is on stage lengths below 600 NM, the lower speeds compared to the A320 permit sufficient margin for most of the conducted flights. It was decided that a minimum cruise Mach number of M0.60 is necessary, while M0.66 would be the preferred cruise speed.

Figure 1 Change of block time for M0.60 and M0.66 compared to A320 mission (M0.76)
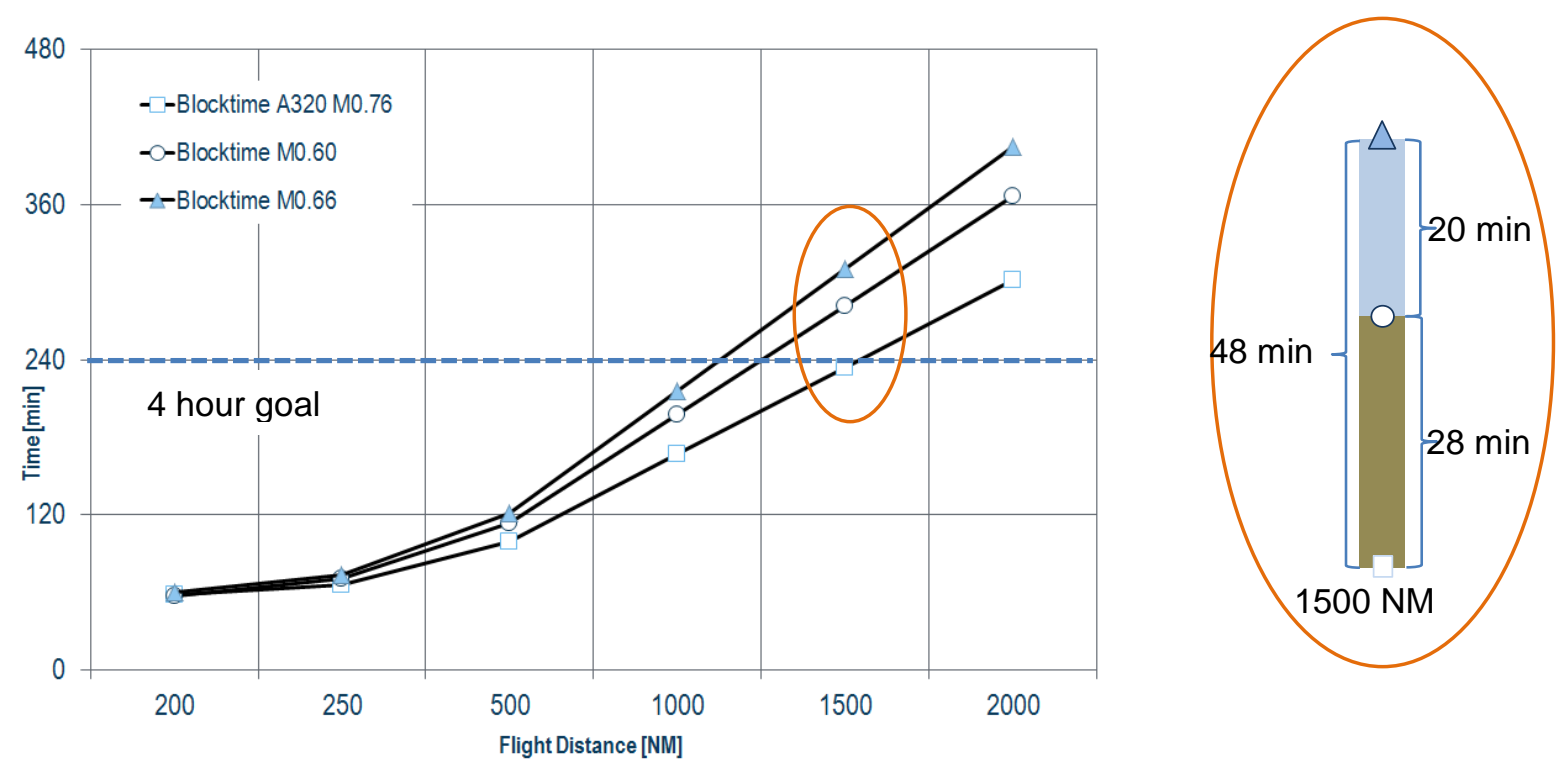
The analysis of available space within the major cities includes possible number of spaces and also their possible length and width of the runway (RWY) shown in Table 2. A deeper analysis was conducted to find the threshold at what length and width of a runway a potential city cannot provide the required space anymore. To minimize the number of these cities, the dimensions were chosen to be relatively low. The runway length was defined as $640 \mathrm{~m}$ and a width of $80 \mathrm{~m}$. This width serves as the maximum width of the airport. The runway width amounts to $30 \mathrm{~m}$. Furthermore the atmospheric conditions at which the aircraft has to comply with the requirement at Maximum Take-off Weight (MTOW) was set at a pressure altitude of $2,000 \mathrm{ft}$ and a temperature of ISA+10K to provide additional safety margin for operation on most airports.

Table 2 Overview of investigated data

\begin{tabular}{|c|c|c|c|c|c|c|c|c|}
\hline \multirow{2}{*}{ Region } & \multirow{2}{*}{$\begin{array}{l}\text { No. } \\
\text { investigated } \\
\text { cities }\end{array}$} & \multirow{2}{*}{$\begin{array}{l}\text { Avg. number of } \\
\text { potential airports }\end{array}$} & \multicolumn{3}{|c|}{ RWY length [m] } & \multicolumn{3}{|c|}{ RWY width [m] } \\
\hline & & & Min & Avg. & Max & Min & Avg. & Max \\
\hline Europe & 34 & 5.8 & 570 & 1341 & 5300 & 80 & 124 & 500 \\
\hline Asia & 40 & 3.6 & 600 & 980 & 3000 & 80 & 122 & 260 \\
\hline North America & 25 & 3.4 & 580 & 1230 & 3000 & 80 & 133 & 880 \\
\hline
\end{tabular}

The definition of a requirement for the noise signature of the aircraft is based on the ICAO specifications and the Flightpath 2050 goals (European Commission, 2011) that aim to reduce the perceived noise emission of flying aircraft by $65 \%$ compared to the year 2000. The limits active in the year 2000 are found in Chapter 3 of the ICAO Annex 16 (ICAO, 2005) stating a cumulative noise level of 281 EPNdB for the MTOW-class of the aircraft. Since inner-city operations do most likely demand bigger noise reductions, it was decided to use the Chapter 4 values, active since 2006, as a baseline stating a limit of $271 \mathrm{EPNdB}$. Interpolating the goal defined by Flightpath 2050 for the year 2040 leads to a $52 \%$ reduction which equals a cumulative noise requirement for the aircraft of $239 \mathrm{EPNdB}$.

Summing up, the ATLeRs deemed necessary for the success of the aircraft are defined below.

- $\quad$ The vehicle must accommodate 60 passengers in a single class arrangement

- Maximum range not less 1,500 NM at a load factor of $90 \%$ (equals 54 Passengers - PAX)

- $\quad$ Take-off Field Length (TOFL) and Landing Field Length (LFL) less than or equal to $640 \mathrm{~m}(2,100 \mathrm{ft})$ at ISA $+10 \mathrm{~K}$ and a pressure altitude of $2,000 \mathrm{ft}$

- $\quad$ Cruise speed of not less than M0.6 on design range

- $\quad$ Time to climb to cruise altitude of no more than 25 minutes

- $\quad$ Cruise altitude higher than $31,000 \mathrm{ft}$ to permit operational flexibility and overfly weather 
- Maximum dimensions driven by airport apron space constraints (Urban, 2016) of 28m wingspan and $24 \mathrm{~m}$ length

- $\quad$ Noise reduction by $52 \%$ compared to the ICAO Chapter 4 (239 EPNdB)

- $\quad$ Certification rules according CS-25 and FAR 25 transport category

- Turnaround time of 15 minutes

- The vehicle must operate at conventional airports with no negative impact on processes and capacity and only minor infrastructural requirements

- $\quad$ Reduction of $\mathrm{CO}_{2}$ by $55 \%$ compared to the year 2000 interpolated from the Flightpath 2050 (European Commission, 2011) and SRIA (Strategic Research and Innovation Agenda, ACARE, 2012) goals resulting from propulsion and airframe improvements

\section{State of the Art Aircraft Assessment}

During the definition of the ATLeRs, an analysis of existing aircraft with similar characteristics was performed to evaluate the design space of the concept. The aircraft analysed are shown in Table 3.

Table 3 Statistical overview of regional aircraft in comparison with CityBird ATLeRs

\begin{tabular}{lcccccc}
\hline Aircraft name & PAX & $\begin{array}{l}\text { Wing } \\
\text { loading } \\
{\left[\mathbf{k g} / \mathbf{m}^{2} \text { ] }\right.}\end{array}$ & $\begin{array}{l}\text { TOFL } \\
\text { [m] }\end{array}$ & $\begin{array}{l}\text { Cruise } \\
\text { speed } \\
\text { [KTAS] }\end{array}$ & $\begin{array}{l}\text { Range } \\
\text { [NM] }\end{array}$ & $\begin{array}{l}\text { Cumulative } \\
\text { noise [EPNdB] }\end{array}$ \\
\hline ATR 72 & 68 & 360 & 1224 & 275 & 785 & 255 \\
An 24 & 50 & 280 & 1650 & 257 & 1115 & 274 \\
Transall C-160 & 77 & 318 & 751 & 277 & 1000 & - \\
Dash 8 & 40 & 303 & 1300 & 360 & 1362 & 257 \\
Fokker 50 & 60 & 327 & 1050 & 287 & 1110 & 262 \\
Dornier 328 Prop & 33 & 350 & 1088 & 335 & 707 & 261 \\
Dornier 328 Jet & 33 & 392 & 1367 & 398 & 950 & 258 \\
ATR 42 & 48 & 306 & 1041 & 270 & 456 & 248 \\
Mean & 51 & 330 & 1181 & 307 & 936 & 259 \\
CityBird (ATLeRs) & 60 & 350 & 640 & 381 & 1500 & 224 \\
\hline
\end{tabular}

The table shows that the ATLeRs are comparable to other existing regional aircraft. The higher wing loading compared to the mean value combined with the low requirement for TOFL, which is almost half the average, as well as the noise limit poses the greatest challenges to this point. Furthermore the cruise speed is 74 KTAS above the average of the investigated aircraft. This is mainly due to the fact that most of the vehicles are turboprop aircraft and therefore operate in a slower cruise speed regime. To achieve these ambitious targets it requires the use of new technological advancements incorporated into the aircraft. 


\section{Concept Description}

The aircraft concept features a tricycle, monoplane, twin-turbofan with podded mountings on the upper aft section of the fuselage and a U-shaped empennage. The low wing configuration is unswept with leading and trailing edge high lift devices along the whole span (excluding winglet). The pressurized fuselage requires a cockpit crew of two and the cabin accommodates two flight attendants. The aircraft has two type B exit pairs in the front and aft section and a small baggage compartment in the tail section of the fuselage. The configuration accommodates up to 60 passengers in a single class. The landing gear is retractable with the nose and main gear in twin wheel configuration. The power plant is a Composite Cycle Engine (CCE) with an Ultra-High Bypass Ratio (UHBPR) (Kaiser, 2015). The flight control system is a 3axis Fly-by-Light system, electrically actuated and employing full envelope protection. The aircraft is designed to comply with CS-25 and FAR 25 airworthiness regulations and adheres to 90 minutes Extended Twin Operations (ETOPS). Figure 2 presents an artist's illustration of the aircraft concept.

Figure 2 Artist's illustration and overview of technical features

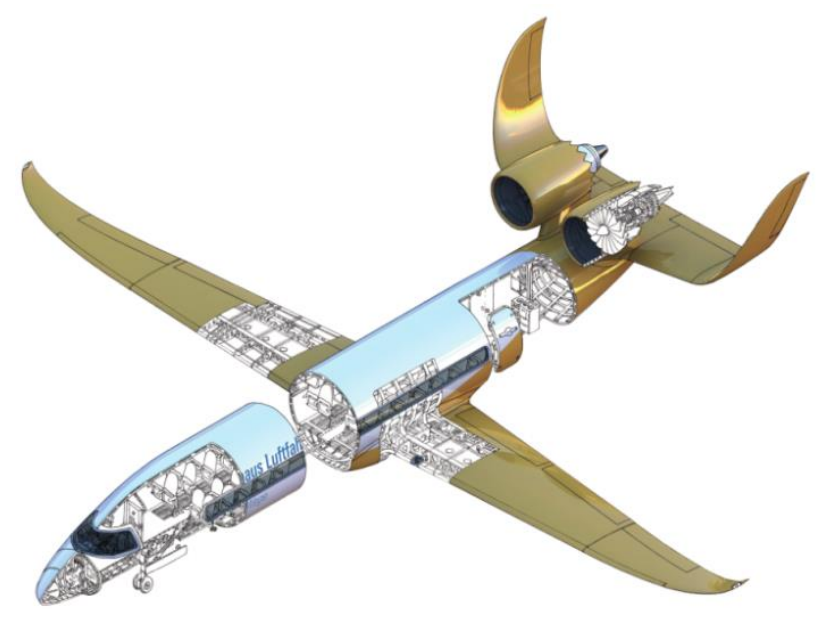

The configuration is driven by the many requirements set for the project. Main drivers were the necessities for Short Takeoff and Landing (STOL) and low noise emission to enable inner-city operation. Furthermore, the compatibility with the inner-city airport, as well as conventional airport and increased fuel efficiency compared to a year 2000 reference has to be ensured. Synergies were created in terms of low speed performance. The low approach speed enables short LFL and also reduces the aircraft source noise, since the major airframe noise sources grow very strong, with powers between 4.5 to 6 (Dobrzynski, 2008) to the flight speed. Eqn (1) shows that a $20 \%$ reduction in approach speed leads to a reduction of $6 \mathrm{~dB}$ overall aircraft noise (Bertsch, 2013):

$$
\Delta L=55 \cdot \log _{10}\left(\frac{V_{A P P_{\text {new }}}}{V_{\text {APP }} \text { ref }}\right)
$$


The STOL requirement stands contrary to cruise efficiency and low noise emissions. A STOL design in general can be enabled through an efficient high lift system, a low wing loading and low sweep. An efficient high lift system that produces a high maximum lift coefficient generally has a high noise signature (e.g. multi-slotted flaps and slats) (Bertsch, 2013), (Pollenske, 2014, Fischer, 2006). Figure 3 shows that a wing loading of $450 \mathrm{~kg} / \mathrm{m}^{2}$ would not only lower the Maximum Take-off Weight (MTOW) by $2 \%$ compared to a wing loading of $350 \mathrm{~kg} / \mathrm{m}^{2}$, but also increases the Specific Air Range (SAR) by $6.2 \%$. The unswept wing was chosen to enable good low speed performance (Torenbeek, 1982) but lowers the cruise speed due to a lower critical Mach number described in the simple wing sweep theory (Torenbeek, 1982).

Figure 3a Change of TOW and SAR with wing loading and SAR

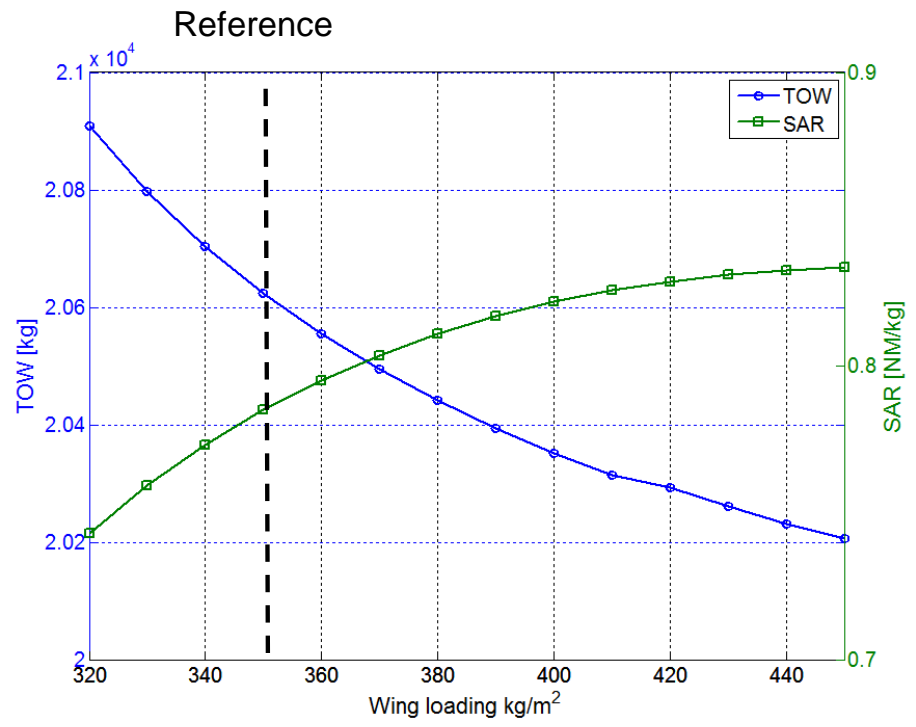

Figure $3 \mathbf{b}$ Impact of a change in MTOW on aspect ratio

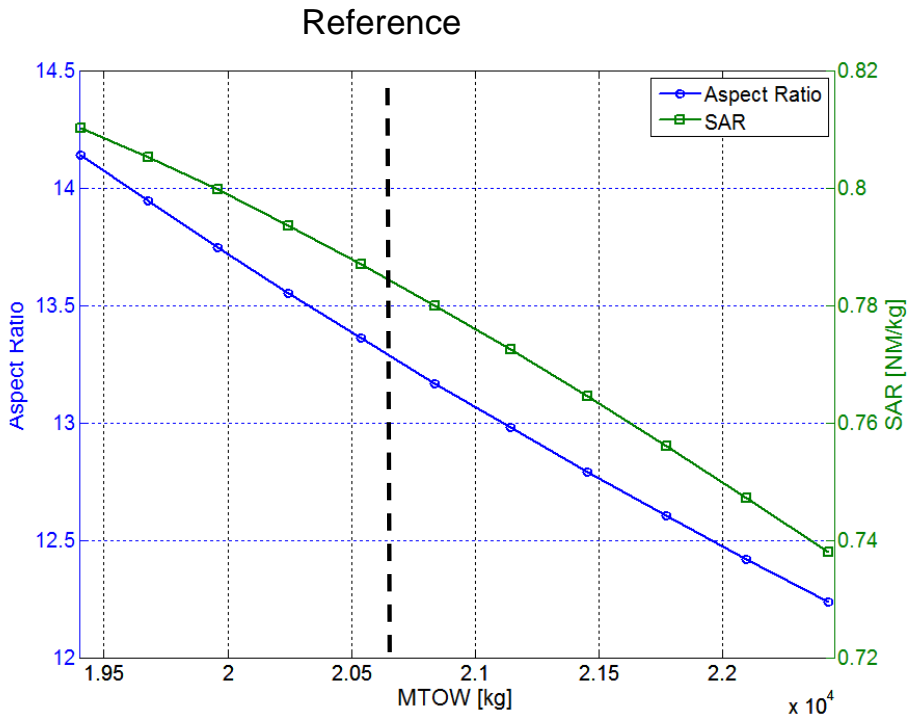

Key driver for the engine positioning has been the benefit through noise shielding, that offers a significant reduction potential (Dewitte, 2016, Frota, 2011) on noise intensities, especially below the aircraft. The engine was positioned on the aft upper fuselage outside the fuselage boundary layer. In conjunction with the $\mathrm{U}$-tail configuration, the surfaces provided by the fuselage, the horizontal stabilizer and fin deflect the noise coming from the engines. However, the disadvantage of this configuration is an expected higher interference drag of the overall aft layout consisting of engines, pylons and empennage and the thrust dependent pitching moment. The side-by-side arrangement of the engines as used in many conceptual studies (Frota, 2011, Bertsch, 2013) poses the danger of uncontained engine failure that impairs functionality of the other engine. Mitigation of this failure risk is addressed in (Frota, 2011), by use of high-energy absorbing materials. This imposes a weight penalty on the aircraft, but enables the efficient noise shielding of the engines in the first place. A further way to mitigate the problem is by longitudinal staggering, which was not evaluated during the design process. Furthermore, a strong dependency comes from the constraints on the aircraft dimensions. Considering a constant wing loading and a maximum span width of $28 \mathrm{~m}$, the MTOW has a direct impact on the aspect ratio and the induced drag, 
which results in a decreased SAR (Figure 3). Lowering the MTOW by $1 \%(206 \mathrm{~kg})$ increases the aspect ratio by $0.44 \%$ and the SAR by $0.28 \%$.

The low wing layout and the engine position enable a wing integrated landing gear which is of short length, contributing to a low weight and noise emission. It also reduces the cabin floor sill height. As it is well below $1.8 \mathrm{~m}$ (6 feet), the aircraft does not need emergency slides (EASA, 2007).

\section{Airframe Technology Assessment and Selection}

As seen in the statistical overview (Table 3), the desired performance of the aircraft in terms of STOL and noise emissions are the most challenging. To resolve this matter, technological advancements need to be implemented. Therefore basic studies of changes in zero-lift drag $C D_{0}$, induced drag $C D_{i}$, maximum lift coefficient $C L_{\text {max }}$, structural weight and thrust specific fuel consumption TSFC were performed to obtain sensitivities on overall aircraft level and see, if the concept differs in some of the characteristics compared to conventional aircraft. This first analysis automatically sizes the overall aircraft according to the changes but does not include detailed effects of how an improvement is achieved (e.g. lower CDi through higher aspect ratio) and how it might affect other parameters such as weight or TSFC. The improvements adhere to the formula, Eqn (2), for the specific air range (SAR), where $V$ represents the flight speed, L/D, the lift to drag ratio, $m$, the mass, $g$, the gravity acceleration and TSFC the thrust specific fuel consumption.

$$
S A R=\frac{V \cdot L / D}{m \cdot g \cdot T S F C}
$$

Figure 4 shows the impact of a change in $C D_{0}$ and $C D_{i}$ on the $S A R$ at begin of cruise. The $C D_{0}$ has a stronger impact on cruise performance than the induced drag improvement. The quasi linear character of the plots offers the possibility to calculate a gradient shown in the diagram. It is clearly visible that the impact of a change in $C_{0}$ is about four times as strong as a change in $\mathrm{CD}_{\mathrm{i}}$. This ratio is higher than usual, due to the low wing loading for the desired cruise Mach number. It is therefore recommended to improve $C D_{0}$ rather than $C D_{i}$. The same analysis with the change of trip fuel, including the overall mission shows the same results, with a slightly less pronounced effect for both $C_{0}$ and $C D_{i}$ on a 500 NM offdesign mission. 
Figure 4 Impact of changes in zero-lift drag $\mathrm{CD}_{0}$ and induced drag $\mathrm{CD}_{\mathrm{i}}$ on the design mission

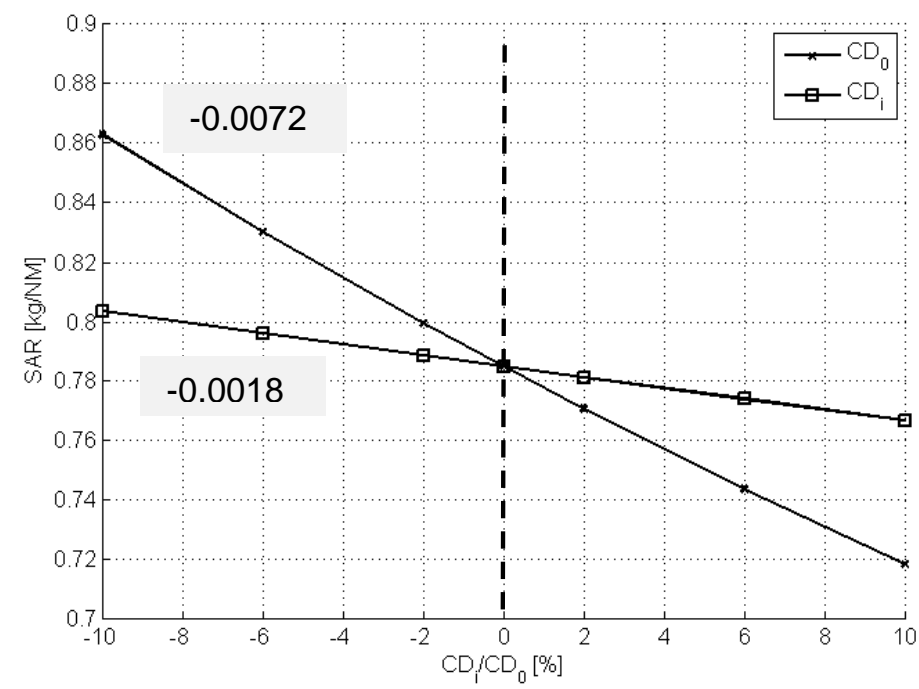

Figure 4 shows the effect of an increased maximum lift coefficient on the SAR in cruise. Since wing loading is mainly driven by the runway length constraint, an increase in $C L_{\max }$ could increase wing loading for a constant $L F L$, thereby increasing cruise performance. The more efficient the high lift system, the higher the SAR value. But as mentioned before, a balanced design is required, since a more efficient high lift system leads most probably to higher noise emissions.

Figure $5 \quad$ Impact of increased CLmax on SAR with constant LFL

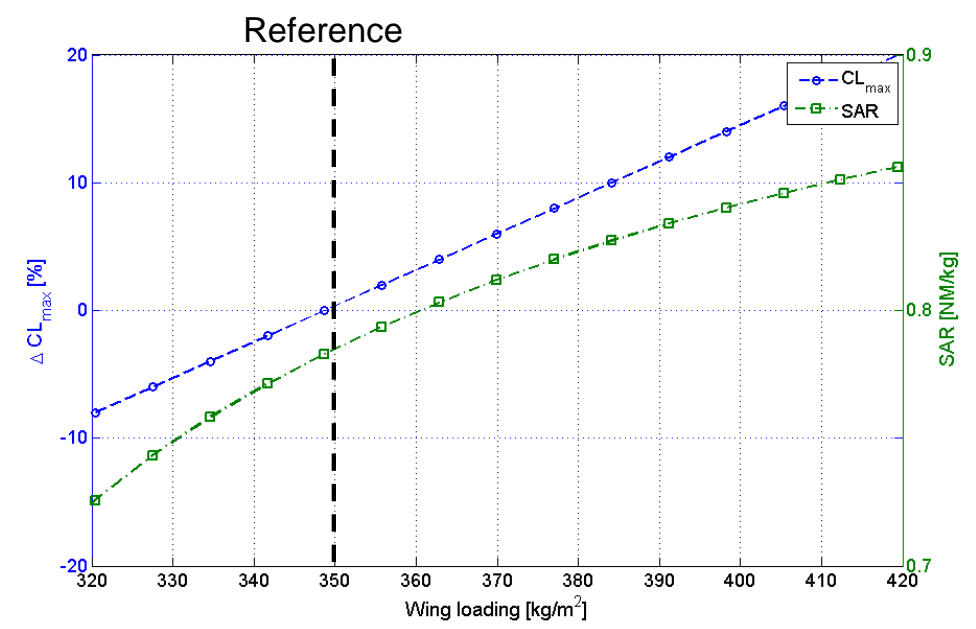

Figure 6 shows the impact of weight and TSFC on the SAR. A significant impact of change in TSFC is shown. A trend that is foreseeable and currently shown in the A320neo attaining most of its efficiency gain from engine improvements. The impact of structural weight is of low relevance to SAR, even on low range off-design missions. 
Figure 6 Impact of changes in TSFC and structural weight on SAR

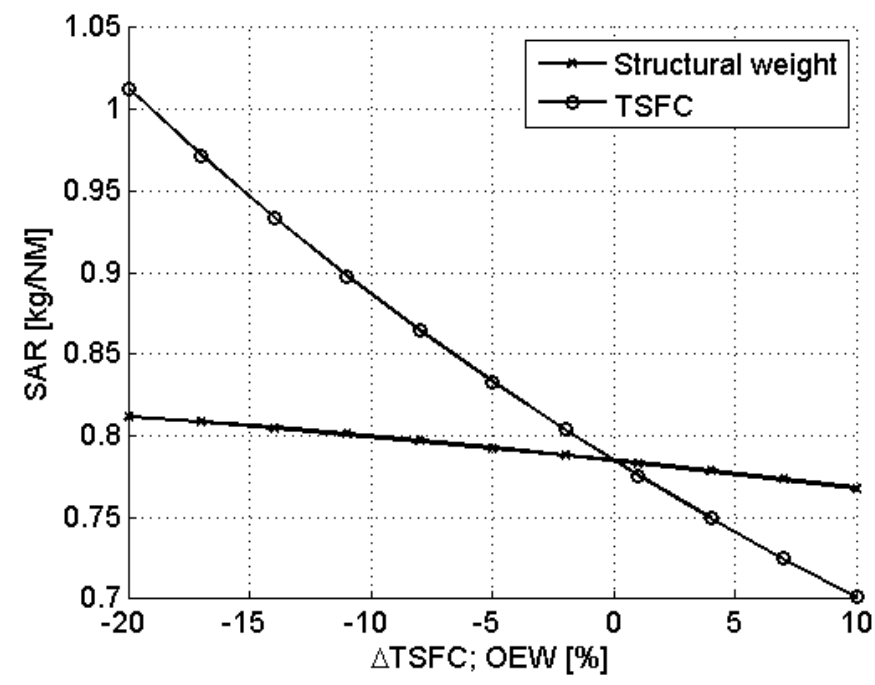

The preliminary analysis serves as a guide on the further implementation of technologies. It indicated strong improvement potential for a higher propulsive efficiency. Furthermore the second strongest effect can be achieved by reducing zero-lift drag. The share of zero-lift drag on the overall drag of this concept is about $50 \%$ higher in cruise flight, than on an A320 for example, causing a bigger impact in the analysis but enabling the required field performance and noise constraints. This is driven by the low wing loading, leading to a higher wing area. Therefore, the share of induced drag is equivalently reduced in cruise flight. This relation offers the possibility that improvements in the maximum attainable lift coefficient will also greatly benefit the overall aircraft performance by simultaneously increasing the wing loading. Therefore, a strong impact between $C L_{\max }$ and $C D_{0}$ exists. Since a certain change in $C L_{\max }$ is more easily obtainable than a $\mathrm{CD}_{0}$ or $\mathrm{TSFC}$ reduction in the same magnitude this poses a great potential for improvement. Table 4 shows the summary of the impact through changes analysed in this preliminary study.

\begin{tabular}{lc}
$\begin{array}{c}\text { Table } 4 \\
\text { Type }\end{array}$ & Overview of preliminary analysis \\
& $\begin{array}{l}\text { SAR increase } \\
\text { for } \pm 1 \%\end{array}$ \\
\hline TSFC & \pm 0.0092 \\
CD $_{0}$ & \pm 0.0072 \\
CL $_{\max }$ & $\pm 0.0052^{*}$ \\
CD $_{\text {i }}$ & \pm 0.0018 \\
Structural weight & \pm 0.0015 \\
\hline
\end{tabular}

*linear approximation at wing loading of $350 \mathrm{~kg} / \mathrm{m}^{2}$

Based on the analysis a set of technologies was selected to fulfil the requirements. For choosing technologies it was decided to prefer simple and less complex technologies. They are usually lower in weight and maintenance, and provide higher operational reliability. The limited space at the airport and tight ground schedule calls for an aircraft with a high operational reliability. 
Due to the high importance of a change in TSFC, a radical engine concept (CCE) was chosen improving this value but also adding weight to the propulsion system. The technology is presented in detail in section "propulsion system".

The reduction of $\mathrm{CD}_{0}$ was conducted through two different measures. A natural laminar flow nacelle lowers the zero-lift drag of the nacelle. This technology is already in use today on the Boeing 787 with prospects to further delay the boundary layer transition in future applications (Norris, 2006, Barry, 1994). Due to the high bypass ratio of the engine, the wetted area increases, rendering the application of natural laminar flow on the nacelle necessary and reducing trip fuel on the design mission by $2.4 \%$. The reduction of fuselage drag was a further measure to increase aerodynamic efficiency since it has the biggest share of wetted area on the aircraft. The reduction of the friction coefficient $\mathrm{C}_{\mathrm{f}}$ is possible through different means. An often discussed method is Riblets, which can be almost weight neutral (Bechert, 2000) and can be applied on about $70 \%$ of the fuselage. A decrease of $8 \%$ (Reneaux, 2004) in $\mathrm{C}_{\mathrm{f}}$ can be obtained leading to a reduction of $1.7 \%$ in trip fuel on the design mission. A major disadvantage is the decreasing efficiency over time (Stenzel, 2011), requiring a high maintenance and cleaning effort. Other drag reduction coatings (Triple $O, 2016$ ) can be applied alternatively, showing a similar benefit. The application of laminar flow technologies on lifting surfaces would promise further improvements, but was not applied. Natural Laminar Flow implies certain airfoil shapes that most probably contradict with high lift requirements. A hybrid laminar flow control system is a very complex system with operational issues to overcome. Due to the fact, that the required power of the compressor is a function of the ambient air density, the activation of the system will be at or slightly below initial cruise altitude. Therefor no contribution can be expected on climb and descent phases, which makes its utilization on a regional aircraft less efficient than on mid or long range aircraft.

The increase of $\mathrm{CL}_{\max }$ is challenging, as it stands contrary to noise reduction demands. This implies that according to (Bertsch, 2013, Fischer, 2006) multi-slotted fowler flaps, slats or powered lift concepts are not feasible. It was therefore decided to make use of an unswept and, due to aft engine location, uninterrupted wing and install a high lift system that runs along the whole span, excluding the winglet. The leading edge device consists of a sealed Krueger flap with no gap between flap and main wing, and the trailing edge uses a plain flap. To support this, the ailerons can be drooped to act as flaperons like on the Airbus A330/A340 series (Sforza, 2014). To energize the boundary layer for prevention of flow separation, plasma actuators were chosen. Although a technology that is controlled actively, the characteristics promise low demands on the power system design, as well as on maintenance and integration of the technology, therefore providing a comparatively low complexity for an active system. Tests with low Reynolds-numbers have shown an increase of $C L_{\max }$ of up to $20 \%$ (Grundmann, 2009). The technology is currently still at a low technology readiness level (TRL) of 4 but offers the advantage that it requires only little power of about $1 \mathrm{~W} / \mathrm{cm}$ along the wingspan (Kriegseis, 2011). Furthermore, the weight impact appears to be very low as well (Opatis, 2012), justifying the use only for operation in the low speed regime and hardly decrease cruise performance. The use of high voltages and frequencies 
during actuation leads to electromagnetic interference (EMI). The Fly-by-Light technology mitigates this problem only partly, requiring further research on this topic. The maximum lift coefficient of the wing was calculated to be $C L_{\max }=3$ with the use of plasma actuators. This is a fairly high value for a slotless high lift system. If necessary, the plain flap system can be replaced with a continuous mold-line link flap, increasing lift capabilities compared to a plain flap and still showing a significant noise reduction (Qing, 2014, Hutcheson, 2008). In general, the high lift configuration is expected to have very low drag characteristics, improving L/D in take-off and approach configuration. This enables a better second segment climb performance, thus reducing noise impact on the ground.

Induced drag was reduced using a high aspect ratio wing. Due to the constraint for span width and a required wing loading for field performance, the aspect ratio is 13.31 at a span width of $28 \mathrm{~m}$.

To augment the take-off process, a catapult system was envisioned assisting the aircraft. This process is outlined in Figure 7. A conventional take-off would be feasible on the short runway but leads to significantly higher thrust requirement of about $40 \%$. The engine would be designed for the take-off case only, adding significant weight to the aircraft, far from the centre of gravity (CG). To avoid the additional weight due to higher thrust requirements, an Electromagnetic Aircraft Launch System (EMALS) (Patterson, 2002) is used, connected to the aircraft via the forward landing gear. This adds much less structural weight to the aircraft, than sizing the engines for the take-off case without a ground system. The system enables a constant acceleration of $4.8 \mathrm{~m} / \mathrm{s}^{2}$. The obstacle clearance height at the end of the take-off was reduced to $3 \mathrm{~m}(9.8 \mathrm{ft})$ since the aircraft is already around $40 \mathrm{~m}(131 \mathrm{ft})$ above ground level, while on the runway. The rejected take-off (RTO) case was considered using the EMALS system to assist in braking. An additional rod, connected to the fuselage between the main gears, decelerates the aircraft. Using only the forward rod for braking would destabilize the aircraft during RTO. On normal take-off, the aft rod has a rotation actuated release mechanism. A deceleration of $5.5 \mathrm{~m} / \mathrm{s}^{2}$ was found necessary for this case. This deceleration can, for redundancy reasons, also be achieved without the EMALS using the normal braking devices of the aircraft but causing higher wear and heat built up in the brakes.

Figure $7 \quad$ Visualization for normal and rejected takeoff (RTO)

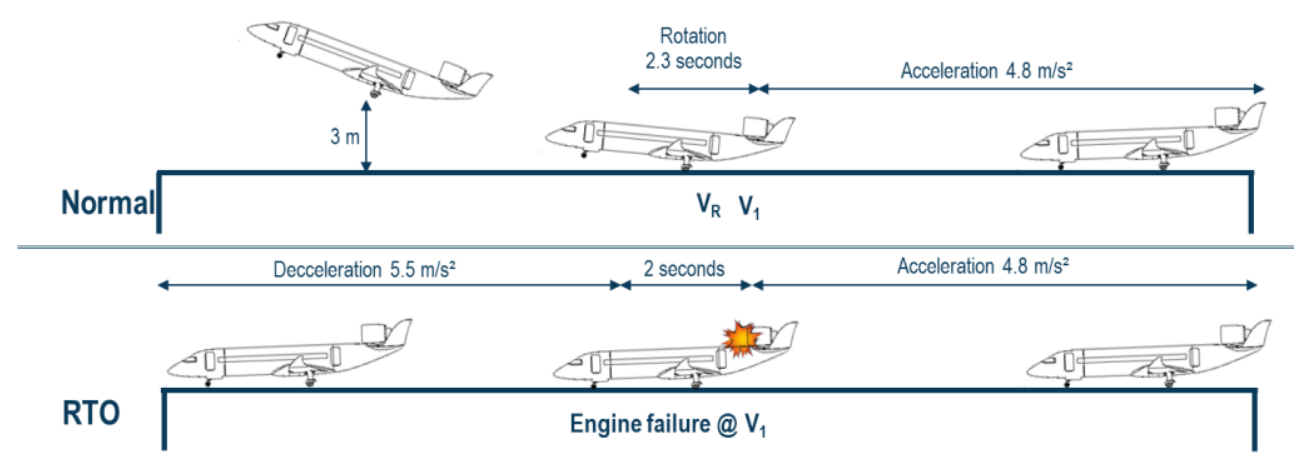


An autoland system with increased navigational capabilities ensures a lower landing field length, due to a lower requirement for touchdown zone length, justifying a lower safety factor than today. A higher approach angle of 5.5 degrees and a slightly increased deceleration of $4.6 \mathrm{~m} / \mathrm{s}^{2}$ further assist the targeted value of $640 \mathrm{~m}$ LFL including safety factors. A ground based emergency braking system proposed by (Matthew, 2009) additionally enhances operational safety.

The potential of weight reduction through CFRP has been discussed in many ways as well as the disadvantages (Bräutigam, 2003, Achternbosch, 2003, Amendola, 2011). The benefits are manifold and the technology is expected to have matured within the timeframe targeted, so that weight reductions of structures can be as high as $20 \%$ compared to today. The furnishing of the aircraft was also reviewed showing potential for weight saving, for example through materials reducing seat weight (Recaro, 2016, Pitch, 2016, Kuhnla, 2011). A further weight benefit can be gained by utilizing Fly-byLight technology, significantly reducing cable weight (Todd, 1990). It also serves as an enabler for advanced flight control schemes by providing a higher bandwidth. Through the use of CFRP the aircraft is more prone to EMI. The immunity to EMI of the Fly-by-Light system makes it a perfect match for the CRFP structures and has reached the TRL 9 with the Kawasaki P-X aircraft already in service (Kawasaki, 2016).

On subsystem level, an all-electric subsystem architecture is used, eliminating hydraulic and pneumatic systems. This enables a bleedless architecture and a power on demand approach for the engine power offtake, increasing system efficiency and improving maintainability. In contrast, a higher weight has to be accepted. For the aircraft, the following systems are supplied by the electric system:

- $\quad$ Anti-Ice System

- Environmental Control System

- Landing Gear (Steering, extension/retraction, braking)

- Avionics

- Flight controls (primary and secondary)

- $\quad$ Cabin (Galley, Lavatory, Entertainment, Lighting)

- Plasma actuators

For the electric subsystem, a first order estimation based on (Isikveren, 2012) was conducted to evaluate weight and power requirements of the sub-components. Powers were estimated according to (Vratny, 2012, Xia, 2011) and the mass via specific powers of all sub-components. This concludes to a maximum power offtake of $135 \mathrm{~kW}$ per engine and a total mass of the electric system of $1,773 \mathrm{~kg}$. 
Table 5 gives an overview of the incorporated technologies and the parameters that the technology is expected to affect in a positive way. It includes the measures taken to reduce the noise emission of the aircraft described hereafter.

Table $5 \quad$ Overview of technologies

\begin{tabular}{lll}
\hline Type & Technology & $\begin{array}{l}\text { Primary } \\
\text { target value }\end{array}$ \\
\hline Aerodynamics & Plasma Actuators & CLmax \\
& NLF nacelle & $\mathrm{CD}_{0}$ \\
& High AR & $\mathrm{CD}_{\mathrm{i}}$ \\
& Coatings/Riblets & $\mathrm{CD}_{0}$ \\
Weight & CFRP & Mass \\
& Furnishing & Mass \\
& Fly-by-light & Mass \\
Subsystems & All electric subsystem & TSFC \\
Propulsion & Composite Cycle Engine & TSFC \\
Noise & Aircraft configuration & Noise \\
& Flap edge treatment & Noise \\
& Sealed Krueger flap & Noise \\
& Acoustic liners & Noise \\
& Chevrons & Noise \\
& UHBPR & Noise \\
\hline
\end{tabular}

\section{Low Noise Aircraft Technologies}

The aircraft's low noise signature is achieved by several measures. The previously mentioned aircraft morphology reduces airframe and engine noise. A general approach was to treat all major noise sources, so that no single component stands out in the overall noise signature during any flight phase. Since it is a conceptual design, detailed noise sources such as cavities were not taken into account. Furthermore, this section explains annexed technologies for noise reduction.

The integration of further technologies to decrease sound generating mechanisms was limited as not to add significant weight or decrease efficiency. Table 5 shows the incorporated technologies. The use of flap edge devices is to reduce the vortex induced noise of the flaps during take-off and in particular during approach. Different ways to treat the side edges are possible, such as side edge fences (Leifsson, 2005), porous tips (Angland, 2009), active side edge blowing (Hutcheson, 2004) or continuous mold-line link (Qing, 2014). A technology that yields almost no impact on weight and aerodynamics with good noise reduction characteristics is the porous side edge. Wind tunnel tests showed a reduction on system level between $0-25 \mathrm{~dB}$ depending on the Strouhal number and therefore the frequency. The engine was treated with proven technologies. These include Chevrons and acoustic liners. A further benefit comes from the UHBPR engine, reducing noise emissions but also shifting the noise pattern from the aft exhaust to the forward fan noise.

\section{Propulsion System}

The propulsion system was designed for the envisaged Entry-Into-Service year 2040. For this time, a fundamental change to the core engine of the propulsion system may be expected in order to meet future emission reduction targets. A 
promising candidate for future aero engine architectures is the Composite Cycle Engine, synergistically combining turbofan components with a piston engine in the high pressure part of the core engine (Kaiser, 2015).

To evaluate the applicability and the benefits of such a novel architecture, a reference geared turbofan has been set up first with assumed year 2035 technology level. Detailed modelling of turbofan and CCE are described in (Kaiser, 2016). The design point for the engine was set at top of $\operatorname{climb}(37,000 \mathrm{ft}$; ISA $+10 \mathrm{~K} ; \mathrm{M0.67})$ with a thrust requirement of $7.61 \mathrm{kN}$. Cycle studies for the reference engine revealed a well-balanced design point for combustion chamber exit temperature $T_{4}=1700 \mathrm{~K}$ and an overall pressure ratio OPR $=49$. The fuel burn optimum specific bypass thrust $v_{\mathrm{s}}$ was $80 \mathrm{~m} / \mathrm{s}$, implying a fan diameter of $1.36 \mathrm{~m}$ (54 in.) and a fan pressure ratio of 1.329 . This results in a thrust specific fuel consumption $\mathrm{TSFC}=12.73 \mathrm{~g} / \mathrm{kN} / \mathrm{h}$.

Looking at the CCE, studies covering changes in specific bypass thrust $v_{\mathrm{s}}$, OPR and $T_{4}$ were conducted and are summarized in Table 6 . The optimum fuel burn improvement was determined at $T_{4}=1400 \mathrm{~K}$ and $\mathrm{OPR}=32$. The parametric study reveals that specific thrust for optimum fuel burn is between $v_{s}=75 \mathrm{~m} / \mathrm{s}$ and $80 \mathrm{~m} / \mathrm{s}$. Furthermore, the study shows how fuel burn can be traded against lower noise. The maximum feasible fan diameter is constrained by the installation space, aerodynamic trade-offs and the noise shielding effect from the fuselage that decreases with increasing engine size. The diameter was found to be $1.52 \mathrm{~m}$ (60 in.). Therefore, specific thrust can be reduced down to $v_{\mathrm{s}}=65 \mathrm{~m} / \mathrm{s}$, reducing source noise by roughly $2.8 \mathrm{EPNdB}$ at the cost of about $0.4 \%$ fuel burn. Therefore, a specific thrust of $v_{\mathrm{s}}=65 \mathrm{~m} / \mathrm{s}$ was chosen for the final design, providing the best compromise of fuel burn and noise improvement as well as installation space. The resulting fuel burn improvement is $17.4 \%$ with an increase in engine weight of $440 \mathrm{~kg}$ compared to the reference turbofan engine, mainly coming from increased fan diameter and from additional piston components in the engine.

Table 6 Parametric studies for specific thrust showing optimum CCE cycles.

\begin{tabular}{llllllll}
\hline Parameter & Unit & Value & & & & & \\
\hline Specific thrust & $\mathrm{m} / \mathrm{s}$ & 85 & 80 & 75 & 70 & 65 & 60 \\
TSFC & $\mathrm{g} / \mathrm{kN} / \mathrm{s}$ & 10.57 & 10.52 & 10.48 & 10.44 & 10.42 & 10.40 \\
Powerplant system mass & $\mathrm{kg}$ & 1580 & 1613 & 1651 & 1692 & 1739 & 1793 \\
Fan diameter & $\mathrm{m}$ & 1.33 & 1.37 & 1.42 & 1.47 & 1.52 & 1.59 \\
Fan pressure ratio & - & 1.354 & 1.329 & 1.305 & 1.282 & 1.259 & 1.238 \\
$\Delta$ Fuel burn vs. turbofan & $\%$ & -17.76 & -17.85 & -17.85 & -17.72 & -17.44 & -16.97 \\
\hline
\end{tabular}

The engine size has been estimated reviewing existing aircraft engines. The nacelle diameter was estimated by reviewing existing engine nacelles. Former studies revealed that CCE length does not increase compared to turbofan engine length (Kaiser, 2015). It was found that nacelle diameter can be expressed as an offset to the fan diameter. The resulting nacelle diameter is $2.01 \mathrm{~m}$ (79 in.). For the length of an engine with a geared fan, a linear relation was derived and a resulting engine length of $3.60 \mathrm{~m}$ (142 in.) was determined. 


\section{Cabin and Fuselage Definition}

The aircraft is equipped with four passenger doors (type B) which are larger compared to contemporary regional aircraft. The cabin layout is designed for 60 passengers in a four-abreast arrangement with a 29.5-inch seat pitch $(0.75 \mathrm{~m})$. A business configuration with 52 seats and 34 inch $(0.87 \mathrm{~m})$ seat pitch would be suited for the maximum design range. Two cabin crew seats are located close to the exits in the forward and aft cabin.

A circular cross-section with an outer diameter of $2.69 \mathrm{~m}(8.8 \mathrm{ft})$ and lower floor position improves the passenger flying experience with a cabin height of $1.97 \mathrm{~m}$ (77.6 inch). Changes to passenger anthropometrics in 2040, in terms of an increase in average height and waist width, were taken into account during the concept phase. The replacement of overhead-bins with small racks for jackets provides a spacious interior perception comparable with larger narrow-body aircraft. The required storage volume is provided below the cabin floor accessible through a hatch, as illustrated in Figure 8. The underfloor stowage is designed to house IATA standard sized luggage. This volume is not available within the proximity of the centre wing box which forces 12 passengers to stow their luggage in the belly hold. The cargo hold, which is mainly used for oversized luggage, is located in the aft fuselage near the bulkhead. The under-seat luggage stowing is realized through a foldable seat concept where the seat pan is pivot-mounted. This allows passenger to stow their luggage while standing in the row which significantly reduces aisle interferences. The seat has a non-recline backrest and a tray table.

Figure 8 Standard 60 passenger cabin configuration with galley and lavatory in the forward cabin (left) and crosssection with underfloor luggage stowing concept (right)
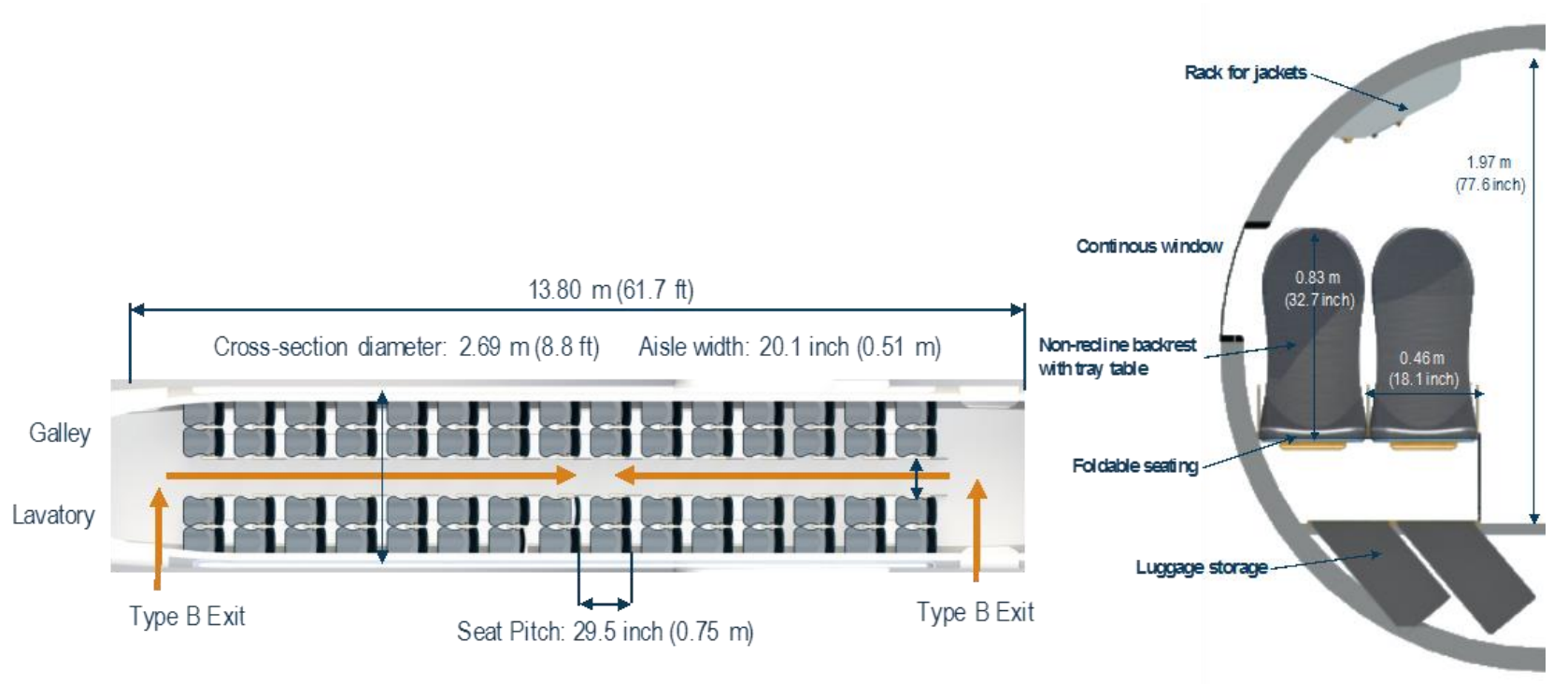

The galley and lavatory are located in the forward cabin allowing accessibility for flight crew and passengers. The galley is sized for drinks and snacks only. Potable water and waste water is contained in contemporary galley trolleys which enables an easy exchange during catering service. This concept applies also for the lavatory. Hence, a potable water and 
waste water tank including the piping system becomes redundant allowing an unrestricted positioning of cabin monuments. A variant with galley and lavatory in the back could permit larger monument sizes with a restricted access to the flight crew.

\section{Performance}

The flight performance of the aircraft is divided into several subsections, dedicated to the challenges and constraints of the concept. An acceptable cruise performance hast to be realized, while the required field performance and low noise targets have to be achieved. Accelerating the transport time, a faster aircraft turnaround is proposed.

\section{Cruise Performance}

General characteristics of the aircraft are presented in Table 7. Basic dimensions and the final layout of the aircraft can be obtained from Figure 9. The aircraft takes full use of the available dimensions defined in the ATLeRs having a span of 28 $\mathrm{m}$ and an overall length of $24 \mathrm{~m}$. The metric of Flightpath 2050 using the fuel burn per passenger and distance for evaluation leads to a value of $0.02485 \mathrm{~kg} / \mathrm{PAX} / \mathrm{NM}$ (which translates to $1.68 \mathrm{l} / 100 \mathrm{~km}$ ).

This amounts to a $29 \%$ reduction compared to an ATR $72-500$ and a $53 \%$ reduction compared to an Embraer E170, representing a slower turboprop and a faster jet powered aircraft respectively. Furthermore a year 2000 (Y2000) reference aircraft was set up to evaluate the improvement. Except for the noise constraints, the Y2000 aircraft has to fulfil the same requirements. A reduction of $49 \%$ is reached when comparing with the Y2000 aircraft. Although a significant reduction in fuel and therefore $\mathrm{CO}_{2}$, it does not fulfil the requirements defined by the Flighpath 2050 goals interpolated for the 2040 timeframe. A further reduction by $11 \%$ or 6 percent points, in relation to the Y2000 platform, has to be achieved to reach the target. The SRIA goals for 2035 regarding the improvements from airframe and propulsion combined (49 \%) are just met for the Y2000 reference platform. Increasing this value, a trade-off would be necessary sacrificing other achievements. 
Table 7 Parametric review

\begin{tabular}{lll}
\hline Parameter & Unit & Value \\
\hline Maximum Ramp Weight & $\mathrm{kg}$ & 20,727 \\
Maximum Takeoff Weight & $\mathrm{kg}$ & 20,624 \\
Maximum Landing Weight & $\mathrm{kg}$ & 19,159 \\
Maximum Zero Fuel Weight & $\mathrm{kg}$ & 18,550 \\
Operational Empty Weight & $\mathrm{kg}$ & 12,350 \\
Maximum usable Fuel & $\mathrm{kg}$ & 4,380 \\
Maximum Payload & $\mathrm{kg}$ & 6,120 \\
Design Payload & $\mathrm{kg}$ & 5,508 \\
Wing Area & $\mathrm{m}^{2}$ & 58.9 \\
Aspect Ratio & - & 13.31 \\
Wingspan & $\mathrm{m}$ & 28 \\
Wing loading & $\mathrm{kg} / \mathrm{m}^{2}$ & 350 \\
Thrust to Weight & - & 0.35 \\
Thrust to Weight T/O (with EMALS) & - & 0.49 \\
Appr. Speed (MLW) & $\mathrm{KCAS}$ & 102 \\
SAR mid cruise & $\mathrm{NM} / \mathrm{kg}$ & 0.787 \\
Fuelburn per PAX and 100km & $\mathrm{V} / 100 \mathrm{~km}$ & 1.68 \\
Range (LF 90\%) & $\mathrm{NM}$ & 1,500 \\
Design Range & $\mathrm{NM}$ & 1,000 \\
Max. PAX & - & 60 \\
Ferry Range & $\mathrm{NM}$ & 2,200 \\
Cruise Mach number & - & 0.65 \\
\hline
\end{tabular}

Figure $9 \quad 3$-view of the aircraft
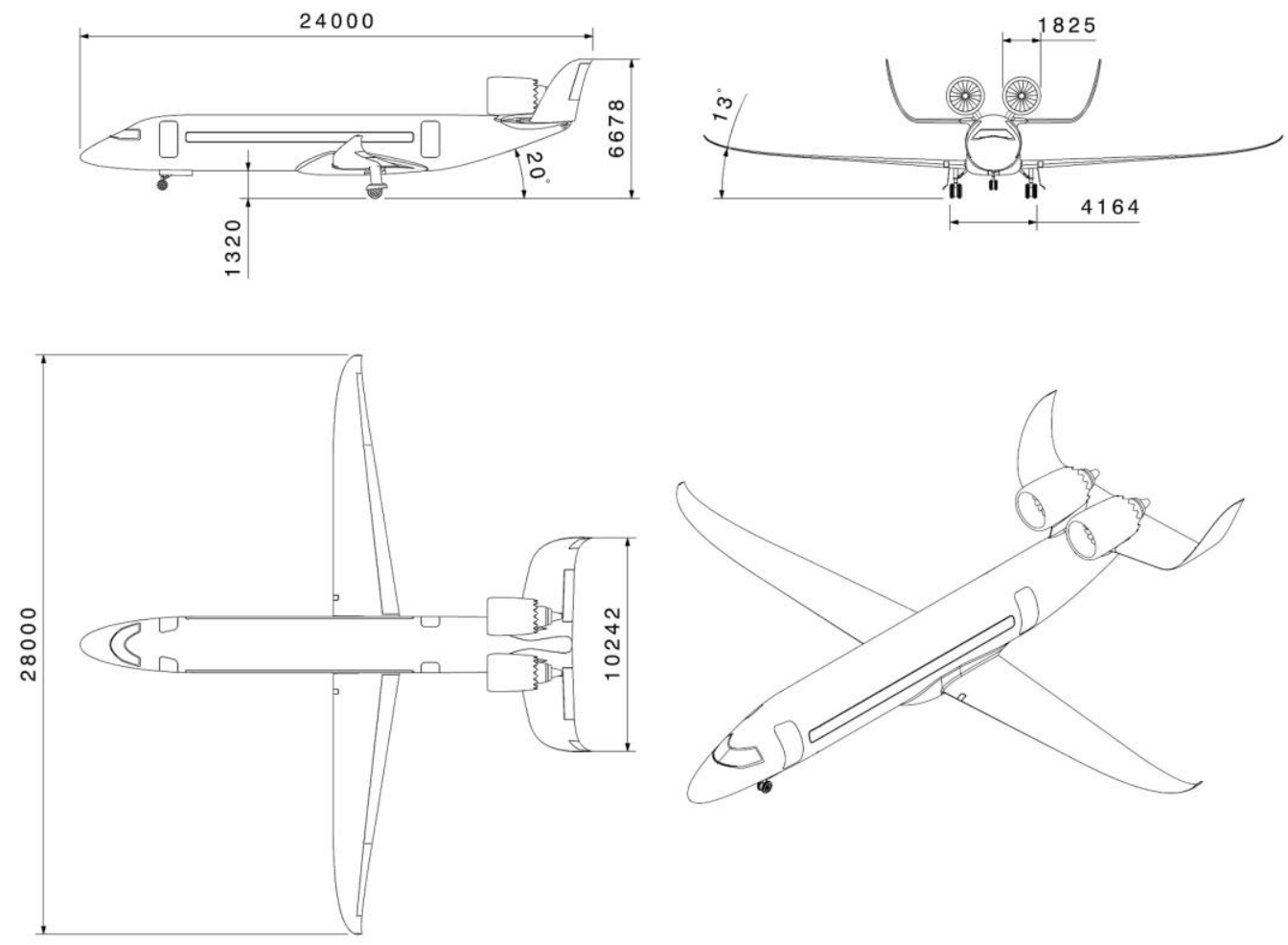
Figure 10 shows the trade-off that had to be made to meet the field performance and cruise speed requirements resulting from the four hour door-to-door goal. An efficient long range cruise, defined as $99 \%$ of max. SAR is only at high weights possible and the efficiency reduces during cruise, leading to step climbs. The initial cruise altitude is FL370 and, therefore, higher than usual, especially when considering the regional utilization spectrum of the aircraft. As shown in Figure 3 and Figure 5 the change of wing loading and $C L_{\max }$ can increase cruise efficiency or enable lower initial cruise altitude.

Figure 10 Cruise Speed optimization

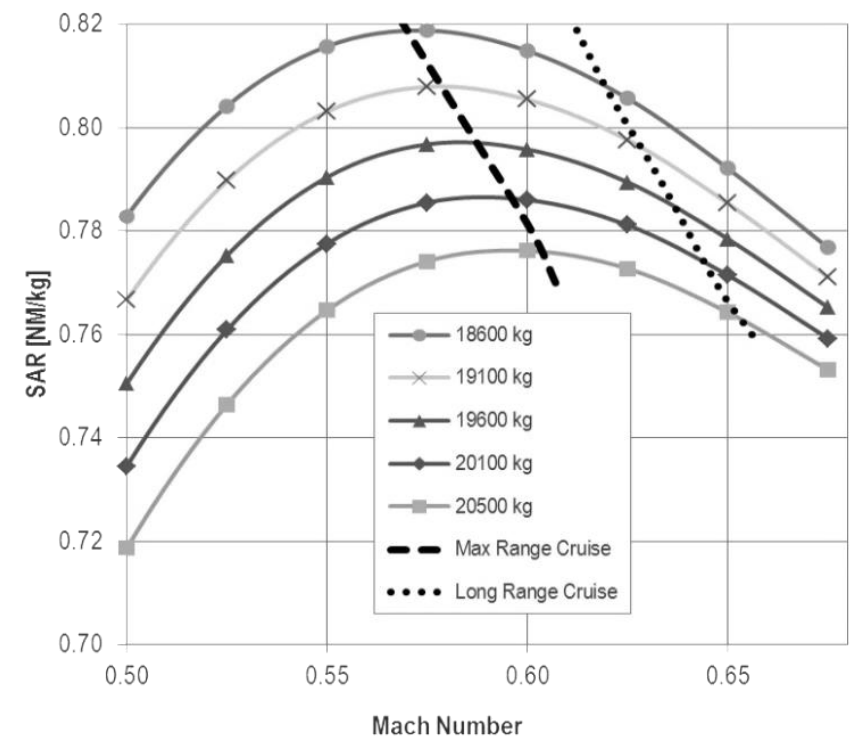

\section{Field Performance}

The low speed requirements were met achieving a TOFL of $532 \mathrm{~m}(1,745 \mathrm{ft})$ using the assisted takeoff system at ISA $+10 \mathrm{~K}$ and a Pressure Altitude (PA) of 2,000 ft, exceeding the required minimum (JAR-OPSa, 2003 ). This provides an additional $20 \%$ safety margin of the runway length.

The landing is not assisted by ground based systems. The reduction of required LFL comes mainly from a steep approach angle, a higher deceleration and the reduction of the safety factor below today's requirement (JAR-OPSb, 2003), justified by advanced avionics and autoland capability. The value obtained for LFL is larger than for TOFL, leading to a smaller margin of only $16 \%$. For conventional airports, the TOFL and LFL are more than twice as high, even at ISA and mean sea level (MSL). The takeoff without assistance requires $1,080 \mathrm{~m}(3,543 \mathrm{ft})$, which fits nicely with the values from comparable

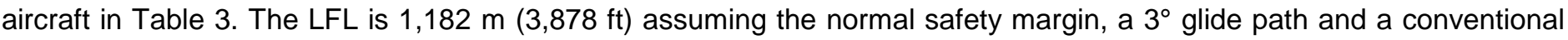
deceleration rate. Table 8 shows an overview of the field performance. 


\begin{tabular}{|c|c|c|}
\hline Low speed Scenario & \multicolumn{2}{|c|}{ Performance Results } \\
\hline TOFL augmented @ISA+10, 2000ft PA & $532 \mathrm{~m}$ & $1,745 \mathrm{ft}$ \\
\hline Safety factor TOFL augmented & 1.2 & 1.2 \\
\hline LFL inner-city ops @ISA+10, 2000ft PA & $553 \mathrm{~m}$ & $1,814 \mathrm{ft}$ \\
\hline Safety factor LFL inner-city ops & 1.16 & 1.16 \\
\hline TOFL conventional @ISA, MSL* & $1,080 \mathrm{~m}$ & $3,543 \mathrm{ft}$ \\
\hline LFL conventional @ISA, MSL* & $1,182 \mathrm{~m}$ & $3,878 \mathrm{ft}$ \\
\hline
\end{tabular}

\section{Low Noise Performance}

In order to achieve the required low noise performance a two-fold approach was selected. Firstly, one target is to reduce source noise, thus the noise emission at the aircraft itself, described in the section "Low Noise Aircraft Technologies" and more detailed in (Heinemann, 2016). Secondly, another target is to optimize the flight procedures to minimize noise impact on the ground. Both approaches are highly relevant in reducing noise in the vicinity of a city airport and are both pillars of the ICAO's Balanced Approach of Aircraft Noise Management (ICAO, 2004).

Generally, aircraft operations show high potentials to reduce airport noise. This applies both for departures and for approaches. Noise abatement departure procedures, for example, can reduce the noise impact by increased climb rates or by continuous climb procedures. The following will present one promising noise abatement approach procedure that can significantly reduce noise in the vicinity of an airport.

Today, aircraft approaching an airport under instrument flight rules follow the glide slope of the Instrument Landing System (ILS). The current glide slope angle of the ILS is $3.0^{\circ}$ at almost all international airports. For the CityBird, a significantly increased glide slope angle of $5.5^{\circ}$ is used, as applied at the London City airport. By increasing the distance between emission point and receiver point the sound level on the ground is reduced. Further sound reducing effects may result from a decreased required thrust of the aircraft's engines.

Calculated noise contours of different glide slope angles are presented in Figure 11. The contours show the maximum Aweighted sound level $L_{\text {Amax. }}$ The sound levels are given in respect to a reference sound level $L_{\text {ref. }}\left(L_{\text {ref }}\right.$ represents a specified noise level as the absolute source noise level of this entirely new aircraft concept is not known. However, the relative differences between the three presented contours due to operational changes are valid.) Different colors represent sound level steps of $5 \mathrm{~dB}$.

Figure 11 shows the corresponding relative sizes of noise contour areas for three different glide slope angles. The results show significant reductions in noise contour areas and thus give evidence of the high noise reduction potential of increased glide slope angles. (Compared to the potential of noise reduction at the source, noise level reduction by increasing the glide slope angle from $3.0^{\circ}$ to $5.5^{\circ}$ may well be in the same order of magnitude or possibly even higher.) 
To conclude, noise reduction by noise abatement approach procedures are a significant and promising means to reduce airport noise. Another obstacle for increased angles of today's aircraft operations lies within the lack of installed navigation systems, e.g. ILS with glide slope angles higher than $3.0^{\circ}$. With an entry into service of 2040 , restrictions from navigation systems can be assumed to be overcome as well, e.g. by the introduction of advanced Ground Based Augmentation System (GBAS).

Figure 11 Noise contours (LAmax) of different glide slope angles of an approaching aircraft

Glide slope angle $3.0^{\circ}$

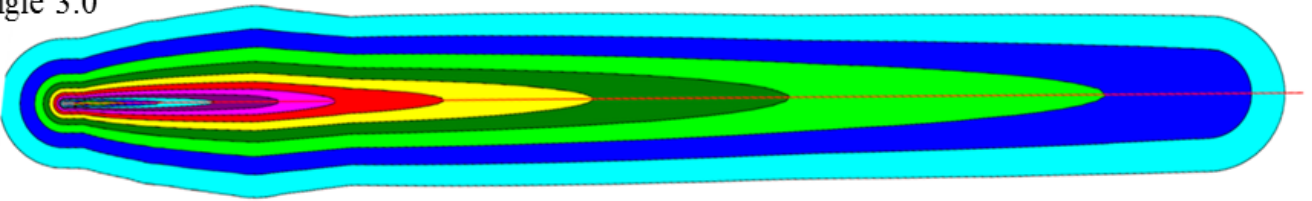

Glide slope angle $4.5^{\circ}$

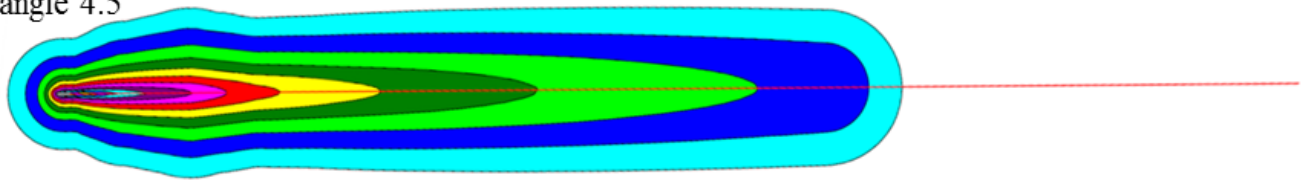

Glide slope angle $5.5^{\circ}$
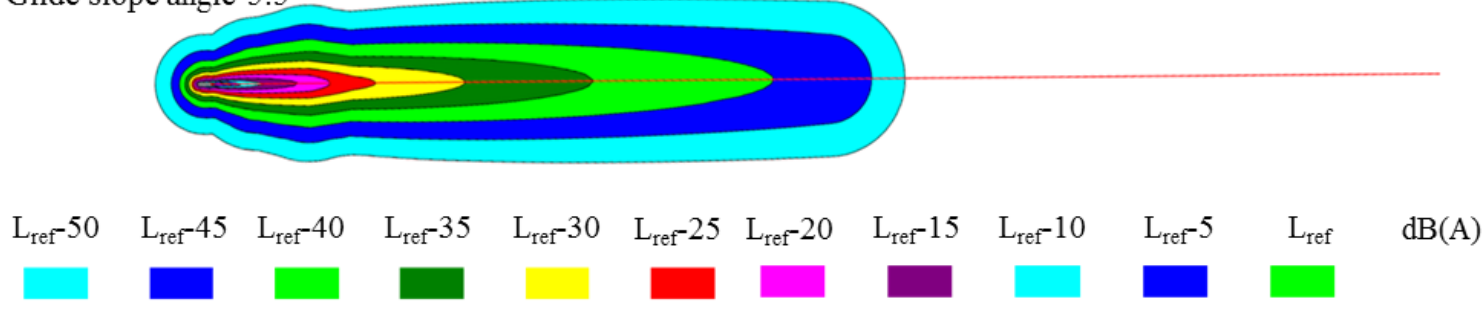

\section{Aircraft turnaround}

The turnaround time is defined as 15 minutes in the ATLeRs which demands a fast passenger boarding and disembarking with simultaneous refueling process. Furthermore, the interface locations are aligned with current best practice (Schmidt, 2015) and ensure the backwards compatibility with existing airport infrastructure.

Figure 12 illustrates the general ground service arrangement for operations at the inner-city airport. A parallel passenger egress and ingress is allowed using displaceable boarding bridges on the left forward and aft door. The inner-city airport disclaims a baggage sorting system to ensure the challenging ATLeRs in terms of passenger access. Passengers can drop their oversized luggage directly at the aircraft entry in designated zones and ground personnel stows the items in the bulk hold. These procedures are already in place for regional aircraft in service with limited stowage inside the aircraft cabin. Cabin service is provided form the right-hand using stairs. The cleaning is usually performed through the aft door and the catering trolleys are exchanged through the forward door. Waste water and potable water is contained in trolleys 
and directly connected to lavatory and galley. This enables an unconstrained location selection due to the independency of the piping system and the abolition of extra service equipment. The ground power plug, located at the aircraft nose, and fuel connector at the wing root is automated with a robot-arm attached to a sub-surface supply. The low fuselage height of around $0.5 \mathrm{~m}$ enables a fast connection mechanism.

Since the apron layout provides parking positions with boarding bridged on the right-hand and left-hand side, the crosscompatibility is ensured with a redundant ground power connector forward and aft, as well as, fuel connectors for both wings.

Figure 12 Ground service arrangement at an inner-city airport

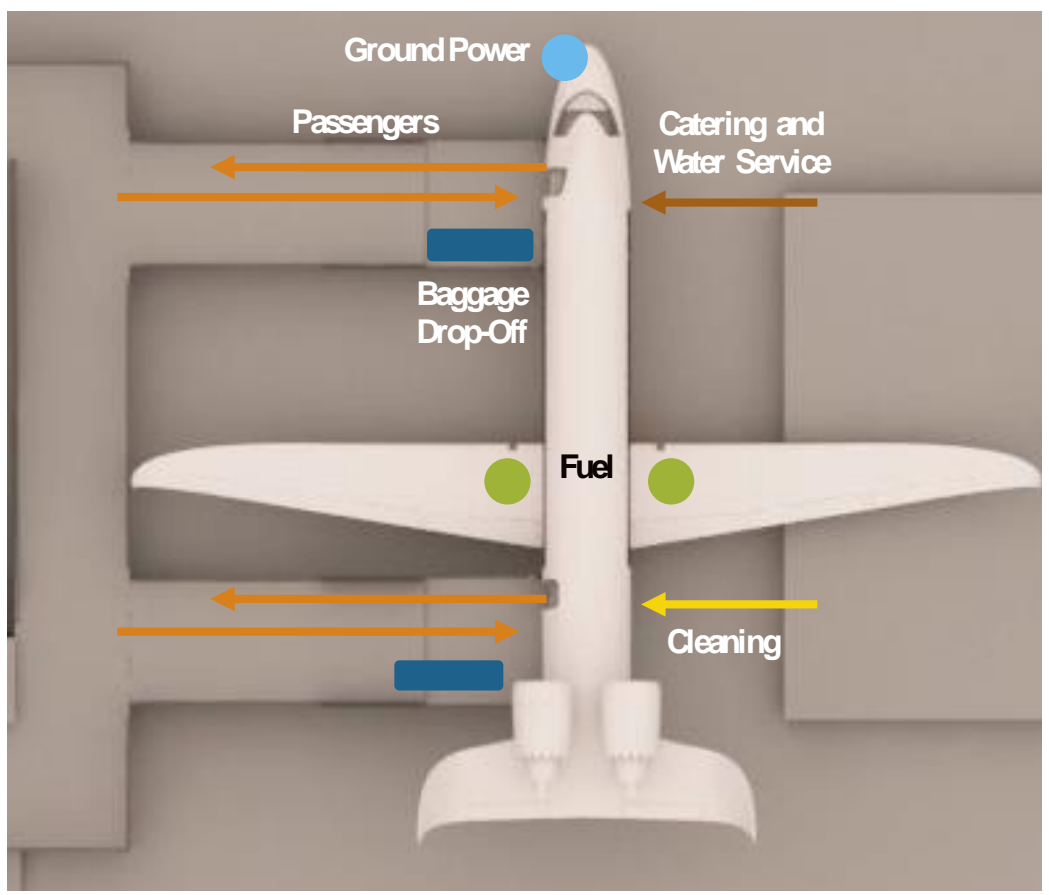

The simultaneous passenger boarding and disembarking with the refueling process is enabled through an installed sprinkler system inside the apron level. The Gantt-chart in Figure 13 breaks down the individual process times of the 14 minute turnaround. The automated positioning and removal of the boarding bridges, ground power and fuel connector requires one minute each. The process times are estimated using methods in (Schmidt, 2016a). The refuelling times results in 7 minutes for maximum payload at design range. This takes into account an exponential decrease in fuel flow due to an increasing static pressure in the tank and drag caused by the closing of valves connecting the installed tanks. The passenger egress and ingress time is based on a passenger flow of $12 \mathrm{PAX} / \mathrm{min}$ per door. First studies using an agent-based passenger flow simulation (Schmidt, 2016b, Schmidt, 2016c), show, that the aforementioned foldable seats could significantly reduce the aisle interferences and required time. For cabin services procedures, the available time without passengers on-board is assumed. Passenger and cabin related processes constitute the critical path. 
Figure 13 Gantt-chart for a standard 14 minute turnaround. The critical path is highlighted in dark colour.

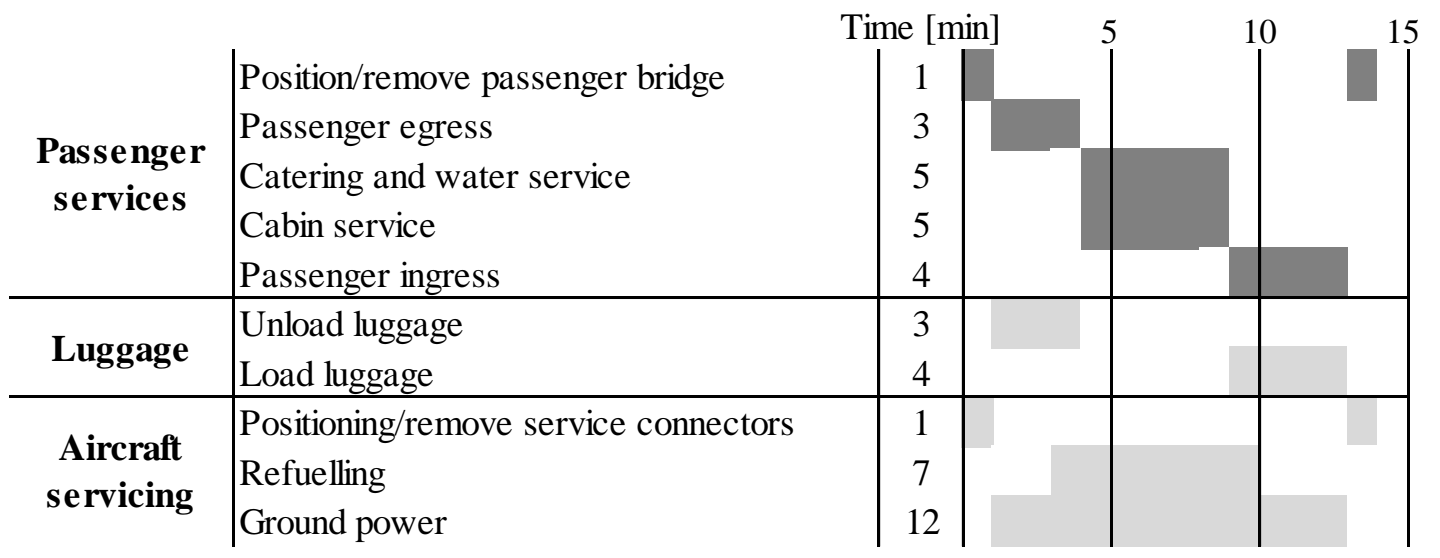

\section{Conclusion}

This paper presented the latest integrated aircraft study from Bauhaus Luftfahrt e.V., dubbed the CityBird. The intent of the design study is to demonstrate a way of achieving the ACARE four hour door-to-door goal and showing the implications on the aircraft. This was accomplished through identification of critical performance values and the application of new technologies. Trade-studies helped defining the final concept.

\section{Further Work}

Future research activities on the platform are manifold. The benefits of an even more efficient high lift system will yield performance improvements. The engines can be optimized to reduce emission, helping to gain acceptance of the proposal, by conducting studies concerning the hybridization of the propulsion system. A family concept with a higher payload and lower range fits very well into the concept increasing passenger flow, still being able to serve most city pairs.

Many measures were taken to achieve a low noise signature. An optimization of dependencies between flight speeds for take-off and landing, technology impacts and independent behaviour of aircraft components probably leads to further improvements (Heinemann, 2016). The analysis of even higher approach angles yields a further reduction possibility.

Furthermore a simplification of the processes will yield a benefit. The usage of taxi bots and a launch system increases efforts in terms of certification and safety considerations. A simplification might therefore benefit the feasibility of the concept. 


\section{Acknowledgments}

As with all design and integration efforts, this paper is a product of a collective effort. In this instance owing to nature of the problem a good measure of innovative thinking and technical excellence was exhibited by the members of the Bauhaus Luftfahrt Inter-disciplinary Design Team. The following are recognized for their most valued contribution to the CityBird and CentAirStation initial technical assessment exercise:

$\begin{array}{lll}\text { Valentin Batteiger, } & \text { Oluwaferanmi Oguntona, } & \text { Raoul Rothfeld, } \\ \text { Julian Bijewitz, } & \text { Annika Paul, } & \text { Christoph Schinwald, } \\ \text { Ingrid Kirchmann, } & \text { Kay Plötner, } & \text { Michael Shamiyeh, } \\ \text { Ulrich Kling, } & \text { Florian Riegel, } & \text { Anne Stroh, } \\ \text { Lukas Miltner, } & \text { Arne Roth, } & \text { Marcia Urban. }\end{array}$

\section{References}

European Commission (2011), “Flightpath 2050: Europe's Vision for Aviation”, Report of the High Level Group on Aviation Research, Publications Office of the European Union, Luxembourg.

Airbus S.A.S. (2012), “Airbus Global Market Forecast 2012-2031”.

Boeing (2012), "Current Market Outlook 2012-2031”.

Airports Council International (2012), "Global Traffic Forecast”, Edition 2013.

International Civil Aviation Organization (2007), "Outlook for Air Transport to the Year 2025", Cir 313 AT/134.

Rolls-Royce (2009), “Market Outlook 2009 - Forecast 2009 -2028”.

United Nations (2010), "World Urbanization Prospects - The 2009 Revision", Department of Economic and Social Affairs, New York, United States of America.

Urban M. et al (2016), „CentAirStation - Multi-modal Transport Hub Concept for Inner-city Airport Operation“, Deutscher Luft- und Raumfahrtkongress 2016, Braunschweig, Germany.

Schmidt M., Ploetner, K.O. (2013) „Forecast Summary“, internal report from Bauhaus Luftfahrt, IB 2013/ 13008.

OAG Worldwide Limited (2012), Official Airline Guide Schedules Data.

International Civil Aviation Organization (2005), “Annex 16 Environmental Protection”, Volume I, Fourth Edition.

Advisory Council for Aviation Research and Innovation in Europe - ACARE (2012), "Realising Europe's vision for aviation", Strategic Research \& Innovation Agenda, Volume 1.

Kaiser, S., Donnerhack, S., Lundbladh, A., and Seitz, A. (2015), "A Composite Cycle Engine Concept with Hecto-Pressure Ratio," 51st AIAA/SAE/ASEE Joint Propulsion Conference, Orlando, FL, USA

Dobrzynski W. (2008), DLR, "Almost 40 Years of Airframe Noise Research", 14th Aeroacoustics Conference, Vancouver 
Bertsch, E.L. (2013), "Noise Prediction within Conceptual Aircraft Design”, PhD thesis, German Aerospace Center (DLR), Institute of Aerodynamics and Flow Technology, Braunschweig.

Pollenske M. (2014), "Slat noise reduction by means of adaptive leading edge devices," CEAS/XNOISE Workshop, , Vilnius, Lithunia.

Fischer, M. Sutcliffe, M. Friedel, H. Gölling, B. (2006), "Low Noise Design Trends Derived from wind tunnel Testing on Advanced High-Lift Devices", 12th AIAA/CEAS Aeroacoustics Conference (27th AIAA Aeroacoustics Conference), AIAA 2006-2562, Cambridge, Massachusetts.

Torenbeek. E. (1982), "Synthesis of subsonic airplane design," Delft University Press, ISBN: 90-247-2724-3.

Dewitte F.H.V. (2016), "Aircraft Noise Shielding," Master Thesis, TU Delft, Delft, Netherlands.

Frota J. et al (2011), "NACRE Final Activity Report”, New Aircraft Concepts Research.

European Aviation Safety Agency (EASA) (2007), "Certification Specification for Large Aeroplanes CS-25", CS 25.810 (a), Amendment 3.

Norris G. (2016), "Boeing plans plain grey natural laminar flow nacelles for $787 \mathrm{~s}$ in bid to reduce fuel burn" Flight International, November 2006; URL: https://www.flightglobal.com/news/articles/picture-boeing-plans-plain-grey-naturallaminar-flo-207769/ [cited: 23 May 2016]

Barry B. et al (1994), "The flight testing of natural and hybrid laminar flow nacelles", ASME 94-GT-408, The Hague, Netherlands

Bechert, D. W., Bruse, M., Hage, W., \& Meyer, R. (2000), "Fluid Mechanics of Biological Surfaces and their Technological Application," Naturwissenschaften, 87(4), 157-171.

Reneaux, J. (2004), "Overview on drag reduction technologies for civil transport aircraft," European Congress on Computational Methods in Applied Sciences and Engineering ECCOMAS 2004, Jyväskylä, Finland.

Stenzel V., Wilke Y., Hage W. (2011), "Drag-reducing paints for the reduction of fuel consumption in aviation and shipping. Progress in Organic Coatings," 70(4), p. 224-229.

Triple O performance solution, Creekmoor, United Kingdom, 18.05.2016, URL: http://www.tripleops.com/benefitstechnical.php, [cited: 23 May 2016]

Sforza P. M. (2014), "Commercial Airplane Design Principles," 1st edition, Elsevier Reference Monographs, ISBN: 978-012-419953-8

Grundmann S., Frey M., Tropea C. (2009), „Unmanned aerial vehicle (UAV) with plasma actuators for separation control,“ in: AIAA-2009-698; 47th AIAA Aerospace Science Meeting, Orlando, Florida

Kriegseis, J. (2011), "Performance Characterization and Quantification of Dielectric Barrier Discharge Plasma Actuators," PhD Thesis, TU Darmstadt, p. 26

Opatis, D.F. (2012), "Dielectric Barrier Discharge Plasma Actuator for Flow Control", NASA, Final Report, NASA/CR2012-217655.

Qing A. (2014), „Airfoil noise reduction using morphing trailing edge”, University of Bristol, The 21st International Congress and Sound and Vibration, Beijing, china.

Hutcheson F., Brooks T., Humphreys W. (2008), "Noise Radiation from a Continuous Mold-Line Link Flap Configuration", 14th AIAA/CEAS Aeroacoustics Conference (29th AIAA Aeroacoustics Conference), Aeroacoustics Conferences.

Patterson, D. (2002), "Design and Simulation of an Electromagnetic Aircraft Launch System", DOI: 10.1109/PSEC.2002.1022384 Conference: Power Electronics Specialists Conference, pesc 02. 2002 IEEE 33rd Annual, Volume: 3.

Matthew A. et al. (2009), „Developing Improved Civil Aircraft Arresting Systems”, Airport Cooperative Research Program Report 29, Chapter 14 
Bräutigam K.-R., Achternbosch M. (2003), "Analyse der Umweltauswirkungen bei der Herstellung, Nutzung und Entsorgung von CFK-bzw. Aluminiumrumpfkomponenten im Flugzeugbau," Tech. - Theor. und Prax., vol. 12, no. 1, pp. 87-92.

Achternbosch M., et al. (2003), "Material flow analysis - a comparison of manufacturing of CFRP-fuselage-components versus aluminium-fuselage-components for commercial airliners," Fresenius Environmental Bulletin 12, p. 656-662

Amendola, A. (2011), "Future aerostructure for the next generation green civil aircraft", Alenia Aeronautica, Aerodays, Madrid

RECARO Aircraft Seating, "SL3510 - The slim lightweight seat for short-haul flights," URL: http://www.recaroas.com/produkte/economy-class/sl3510.html, 2016. [cited: 23 May 2016]

Pitch Aircraft Seating, "Introducing the Pitch PF2000," 2016, URL: http://www.pitchaircraftseating.co.uk/, [cited: 23 May 2016]

Kuhnla W.-D. (2011), "Innovations and Advanced Technologies for the Future Cabin System," Altair Technology Conference.

Todd J. R. (1990), “Fly-by-Light Technology Development Plan”, NASA Contractor Report 181954.

Kawasaki Heavy Industries website, URL: http://global.kawasaki.com/en/mobility/air/aircrafts/p_1.html, 2016, [cited: 31 May 2016]

Isikveren A.T. (2012), "Conceptual Studies of Universally-Electric Systems Architectures Suitable for Transport Aircraft," Deutscher Luft- und Raumfahrtkongress 2012, Berlin, Germany

Vratny P. C. (2012), “A Battery Powered Transport Aircraft,” Saarbrücken: AV Akademikerverlag.

Xia X. (2011), "Dynamic Power Distribution Management for All Electric Aircraft," Cranfield University.

Leifsson, L.T. (2005), „Multidisciplinary Design Optimization of Low-Noise Transport Aircraft”, PhD Thesis, Virginia State University.

Angland D, University of Southampton, „Measurements of Flow around a Flap Side Edge with Porous Edge Treatment,” AIAA Journal, Vol. 47, No. 7 (2009)

Hutcheson F.V. (2004), „Blowing Flap Experiment - PIV Measurements“, NASA Langley Research Center, NASA/TM2004-213240.

Kaiser S., Seitz A., Vratny P., Hornung M. (2016), "Unified Thermodynamic Evaluation of Radical Aero Engine Cycles", ASME Turbo Expo 2016, GT2016-56313, Seoul, South Korea.

Joint Aviation Authorities, Joint Aviation Requirements, JAR OPS 25.113

Joint Aviation Authorities, Joint Aviation Requirements, JAR OPS 1.515

Heinemann P., Shamiyeh M., Plötner K.O., Jeßberger C., Hornung M., (2016): "Conceptual studies of a transport aircraft operating out of inner-city airports", Deutscher Luft- und Raumfahrtkongress 2016, Braunschweig, Germany.

International Civil Aviation Organization ICAO (2004), "Guidance on the Balanced Approach of Aircraft Noise Management", Doc 9829, First Edition.

Schmidt M., Nguyen P., and Hornung M (2015): Novel Aircraft Ground Operation Concepts Based on Clustering of Interfaces, SAE Technical Paper 2015-01-2401, Seattle, Washington State, USA. doi:10.4271/2015-01-2401.

Schmidt M., Paul A., Cole M., Ploetner, K.O. (2016a), "Challenges for ground operations arising from aircraft concepts using alternative energy," Journal of Air Transport Management, doi:10.1016/j.jairtraman.2016.04.023. 
Schmidt, M., Engelmann, M., Brügge-Zobel, T., Hornung, M., and Glas, M. (2016b), "PAXelerate - An Open Source Passenger Flow Simulation Framework for Advanced Aircraft Cabin Layouts," 54th AIAA Aerospace Sciences Meeting, American Institute of Aeronautics and Astronautics, San Diego, California, USA, 2016. doi:10.2514/6.2016-1284

Schmidt, M., Engelmann, M., Rothfeld, R. and Hornung, M. (2016c), "Boarding Process Assessment of Novel Aircraft Cabin Concepts", 30th International Congress of the Aeronautical Sciences (ICAS), Daejeon, South Korea: 2016

\section{Nomenclature}

\section{Symbols}

$\begin{array}{llll}C D_{0} & \text { Zero-Lift drag coefficient } & \text { L/D } & \text { Lift to drag ratio } \\ C_{i} & \text { Induced drag coefficient } & \text { LAmax } & \text { Maximum A-weighted sound level } \\ \mathrm{C} f_{f} & \text { Friction coefficient } & \text { Lref } & \text { Reference sound level } \\ \mathrm{C} L & \text { Lift coefficient } & \mathrm{m} & \text { mass } \\ \mathrm{C} L \max & \text { Maximum lift coefficient } & \mathrm{V} & \text { Speed } \\ \mathrm{g} & \text { gravitational acceleration } & \mathrm{V}_{\text {app }} & \text { Approach Speed }\end{array}$

\section{Definitions, Acronyms and Abbreviations}

ATLeRs $\quad$ Aircraft top Level Requirements

CCE Composite Cycle Engine

CG Centre of Gravity

$\mathrm{CO}_{2} \quad$ Carbon dioxide

EMALS Electromagnetic Aircraft Launch System

EMI Electromagnetic Interference

ETOPS Extended-range Twin-engine Operation

Performance Standards

GBAS Ground Based Augmentation System

ILS Instrument Landing System

LF Load factor

LFL Landing Field Length

MLW Maximum Landing Weight
MTOW Maximum Take-off Weight

OAG Official Airline Guide

PAX Passenger

PA Pressure Altitude

RPK Revenue Passenger Kilometres

RTO Rejected Take-off

RWY Runway

SAR Specific Air Range

SRIA Strategic Research and Innovation Agenda

TOFL Take-off field Length

TRL Technology Readiness Level

TSFC Thrust Specific Fuel Consumption

UHBPRUltra High Bypass Ratio 